\title{
Making the Public Distribution System Work
}

Dr Debarshi Das ${ }^{\dagger}$

\begin{abstract}
Drawing on empirical observations of operation of public distribution system in different states of India, the paper constructs a preliminary game theoretic model. It argues that an effective public distribution must be as universal as possible, delivery mechanism of fair price shops should be reformed, they should be make them commercially viable and that special attention should be paid to PDS at times of high food inflation.
\end{abstract}

Key words: universal public distribution system, fair price shop, expected utility, extensive game, India

\footnotetext{
${ }^{\dagger}$ Assistant Professor, Department of Humanities and Social Sciences, Indian Institute of Technology, Guwahati, Email: debarshi05@gmail.com

(c) 2014 Das. This is an Open Access article distributed under the terms of the Creative Commons Attribution License (http://creativecommons.org/licenses/by/2.0), which permits unrestricted use, distribution, and reproduction in any medium, provided the original work is properly cited.
} 


\section{Introduction}

The Indian parliament passed the National Food Security Bill in 2013. The passage of the bill was preceded and accompanied by animated debates in academic and policy circles. It is important to note that public distribution system has been the topic of debates in India for long. One suspects that the degree of intensity of the debate considerably went up after 1997, when universal public distribution system (UPDS) was discarded in favour of targeted public distribution system (TPDS). Detractors of TPDS have pointed out that the move towards targeting has not succeeded in reducing price volatility. Furthermore, after TPDS has been introduced per capita food availability has gone down. It has become more unstable as well (Sen and Himanshu, 2011).

Nonetheless, it is to be noted that discussions on many dimensions of the PDS went on as the food security bill was on its way. Probably these debates would continue, for the issues that underpin them are by no means settled. Some of the aspects of PDS which have been in discussion are introduction of cash transfer or coupons in lieu of food-in-kind, continuation of TPDS versus switching over to UPDS, extending the coverage of TPDS, identification of beneficiaries, introduction of "aadhar" cards which will collect biometric information of beneficiaries, non-traditional food security measures such as special provisions for lactating mothers, babies and the destitute. On each of these issues, different shades of opinion have circulated. For example, Kotwal et al. (2011) raised important points in favour of cash transfer, which may help in curbing corruption. Soares (2011) and Yanes (2011) discussed the phases which Brazil and Mexico went through while implementing targeted cash transfer. Svederberg (2012) like Kotwal et al. (2012) has argued for targeted cash transfer based on biometric identity validation, as it would curtail wasteful expenses. Khera (2011a) presents survey data of selected states of India pertaining to performance of PDS and argues that there are lessons one can learn from the states which have been successful in implementing PDS. Sen and Himanshu (2011) have presented the case for near-universal PDS whose costs according to them are not much higher than the existing system.

The present article does not intend to cover all, or even a majority, of these evidently salient issues. The aim here is to consider some empirical observations pertaining to the public distribution system. The paper would try to understand the logic behind the functioning of PDS in places it has been running satisfactorily. This would hopefully provide us some lessons on designing a less corrupt system. We shall concentrate on the microeconomic aspects of public distribution system here. A model on the distribution of food in a strategic decisionmaking framework (i.e., a game theoretic model) will be presented to understand the empirical observations. First, we shall discuss some prominent features of PDS as it has been functioning in different states of India. This would be useful to mould the basic contours of the model to be presented subsequently.

\section{Observations}

A notable observation of performance of PDS in India is that those states which are closer to universalising the PDS are more successful in delivering its benefits. In the nine states where Khera (2011a) conducted her survey four are either fully universal (Tamil Nadu and Himachal Pradesh) or quasi-universal (Chhattisgarh and Andhra Pradesh, where about 80 per cent of the population are entitled to PDS commodities). In a different paper, Khera (2011b) has categorised major states of India into three groups: functioning, reforming and languishing, based on per capita purchase of PDS grains. Except Chhattisgarh, which tops in the category of "reforming" states, the other three of the above four states are "functioning" states. In other words, these four states are among the top performers of the country. States with universal PDS are also known to have low leakage or diversion of PDS food (Sen and Himanshu, 2011). A reason for this could 
be that in UPDS everyone has a stake in the smooth functioning of PDS, because everyone is a potential or actual beneficiary (Basu and Das, 2013). For those officials and traders who are in between the release of food from government godowns and the actual point of sale, pilferage of PDS goods becomes difficult when the number of stakeholders rises. In TPDS, not everyone is a beneficiary. A large number of people do not have the incentive to keep it functional. This could be one of the possible explanations for the observed negative relation between universalisation and corruption. There might be others.

Second, to make the system functional the fair price shops (FPS), where PDS goods are distributed, should be commercially viable. After TPDS was introduced, the volume of grain handled by the fair price shops has gone down. The number of beneficiaries has also declined. Both these factors have adversely affected the earning of the dealer. It has been found that this has contributed to pilferage and diversion of PDS food to open market. In Khera's (2011a) survey the states where commission of the dealer has not been revised (Bihar, UP, Jharkhand) are some of the worst PDS performers. It thus appears that giving the dealer an economic incentive could be helpful.

The third observation is regarding monitoring. It has been found that the states which are more vigilant have less corruption. This is an obvious point which needs little elaboration. One may however note some features of pilferage. It is observed that the largest part of PDS grain diversion takes place between the lifting of the stock from Food Corporation of India $(\mathrm{FCl})$ godowns and the FPS. When the dealer is responsible for lifting the stock the chances of diversion rises. This is the reason why many states have taken over the responsibility of delivering the stock to the FPS. In such cases corruption has gone down. Corruption has also reduced when innovative ways to plug the leaks have been experimented and applied. Some of these include institutional changes such as running the FPS by cooperative societies instead of private shop owners. Or it could be the use of information technology, such as informing the beneficiaries directly through SMS via mobile phones about the availability of stock in the FPS (Khera, 2011a).

\section{A Model}

Collating the observations noted above we construct a schematic model. This is a simple game theoretic model involving two parties (or players, as they are called in game theory). We are constructing an extensive game, where the players take their action one after another in a sequential manner. The two players are: (1) the dealer in the FPS, denoted by $D,(2)$ the beneficiary who is entitled to PDS commodities (let us suppose foodgrain), denoted by $B$. Besides these two players, there is a third party, the government, denoted by $G$. We are keeping this model simple, therefore $G$ is not assumed to be a player. In other words, it does not take strategic decisions, nor does it get any payoff from the game. $G$ randomly fixes some value of a variable (elaborated below) in a random manner. In game theory literature Nature is often assigned such roles.

We assume that variable which $G$ decides in the beginning of the game is $\alpha . \alpha$ is the proportion of the population of the country (or state) entitled to buy foodgrain at a rate cheaper than the open market price. $\alpha$ can take any value from 0 and 1 , including the two limits. When $\alpha$ $=1$ PDS is universal. $\alpha=0$ would mean complete dismantling of PDS in its present form. $0<\alpha<1$ implies TPDS.

After $G$ has decided on a particular $\alpha$, it sends corresponding amount of foodgrain to the fair price shops. We are considering the behaviour of a representative of these shops. The dealer of this shop is denoted by $D$. The game has now moved to stage 2 , where it is the turn of $D$ to decide what proportion of foodgrain entitlement he will divert, and sell in the open market. Let us assume that each beneficiary who is entitled to PDS foodgrain is entitled to $F$ amount of foodgrain. $D$ decides a proportion, let us say $\beta$, of $F$ which he would actually sell to the beneficiary. Like $\alpha, \beta$ ranges between 0 and 
1. $\beta=0$ would imply complete corruption. $\beta=1$ would mean zero corruption.

To avoid complications, the quality of grain distributed through PDS is assumed to be same as those available in open market. Once $D$ has decided a particular $\beta$, it means that $B$ would get $\beta . F$ food in the FPS, instead of his legal entitlement $F$. $B$ has two choices, either to purchase it (the action is denoted by $P$ ), or not to purchase it (denoted by NP). Since the quality of PDS grain is same as that of open market, a consumer when offered $\beta$.F of PDS grain would take it because the price in FPS is lower. Thus there would not be any excess unsold supply of PDS grain. It also means that given $\beta>0, B$ in our model would always choose $P{ }^{1}$

As the choice made by the beneficiary is trivial here, we ignore it in the graphical representation of the game below (Figure 1). The payoff of the FPS dealer, $D$, is of special interest. His payoffs are $\beta . F . \pi_{1}+(1-$ $\beta)\left[F . \pi_{3}(1-p)-p . c\right]$ and $(1-\beta)\left[F . \pi_{3}(1-p)\right.$ - p.c] in the diagram. We elaborate them below.

The payoff (or utility) of $D$ assumed to be linear in the money he earns. This also implies that that $D$ is risk neutral, a convenient assumption for this simple exposition. Let us denote his payoff function by $U_{d}$. The profit he makes by selling a unit of PDS grain to $B$ is $\pi_{1}$. If he diverts this to open market, profit per unit rises to $\pi_{3}$ $\left(\pi_{1}<\pi_{3}\right)$. However selling PDS grain in the open market is a risky business and may attract punishment. The punishment may be meted out by the government. It could be more social in nature as well- social boycott for example. The magnitude of punishment when $D$ is caught is given by $c$. Besides paying this fine, $D$ loses the opportunity of making profit by selling the PDS grain. The stock he had assigned for sale in open market, $(1-\beta) F$, is confiscated. Let us

\footnotetext{
${ }^{1}$ An alternative justification could be as follows. Although the quality of PDS grain could be low compared to those available in open market at a higher price, the representative beneficiary $B$ does not have the wherewithal to purchase the latter. Thus he buys $\beta$.F even when it is not of the best quality.
}

assume that the probability that the dealer is found out is given by $p$. Being a number representing probability, $p$ lies between 0 and 1. We make the important assumption that $p$ is a non-decreasing function of $\alpha$. It is also assumed to be a function of $t$, where $t$ represents anti-corruption measures such as switching over to cooperative society managed FPS, SMS alerts etc. Thus,

[1] $p=g(\alpha, t)$, where $\frac{\partial g}{\partial \alpha} \geq 0, \frac{\partial g}{\partial t} \geq 0$

[1] implies when more people have stake in the PDS (high $\alpha$ ) it is easier to detect the corrupt dealer.

With the help of the assumptions made so far, we can write the payoff function of $D$, when $B$ decides to purchase what $D$ sells in the FPS, as,

[2] $U_{d}=\beta . F . \pi_{1}+(1-\beta)\left[F . \pi_{3}(1-p)-p . c\right]$

The explanation is as follows. Since $D$ has decided to sell $\beta$.F through FPS and $\pi_{1}$ is the profit per unit, the first term in [2] is the profit from sale through FPS. By selling $(1-\beta)$ of $F$ in open market, $D$ is entering an uncertain situation. With probability $(1-p)$, he makes per unit profit of $\pi_{3}$. However, with probability $p$ fine $c$ is imposed. The terms in square brackets in [2] represent the expected payoff when $F$ amount of food is diverted. This is multiplied with $(1-\beta)$ because that is the proportion of $F$ which is diverted.

When the consumer does not purchase FPS grain, the allotment assigned for FPS distribution (i.e., $\beta F$ ) is taken back. Thus, the first part becomes zero. $D$ still earns money by diverting a part of the allotment. So, his payoff here is,

[3] $U_{d}=(1-\beta)\left[F . \Pi_{3}(1-p)-p . c\right]$

Given that the beneficiary chooses $P$ in equilibrium, [3] becomes irrelevant. In short, the dealer would concentrate on [2] and try to maximise it by choosing an appropriate $\beta$.

Notice that [2] is the weighted average of $F . \pi_{1}$ and $F . \pi_{3}(1-p)-p . c$ with the weights $\beta$ and $(1-\beta)$. This implies that if

[4] $F . \Pi_{1}>F . \pi_{3}(1-p)-p . c$ 
$D$ would choose $\beta=1$. If,

[5] $F . \Pi_{1}<F . \Pi_{3}(1-p)-p . c$

$D$ would set $\beta=0$. If,

[6] $F . \Pi_{1}=F . \Pi_{3}(1-p)-p . c$

any value of $\beta$ is optimal.

If the profit of selling the food entitlement through FPS is higher than the expected payoff of diverting it, the dealer does not divert any part of it: $\beta=1$, or zero corruption. If the latter is greater than the former, he diverts all of it: $\beta$ $=0$, complete corruption. If the two are equal, he is indifferent between selling through FPS or diverting.

This simple model gives us corner solutions. That is, the dealer either diverts fully or he does not divert at all. In the third case he may divert partially (case [6]). But this would occur in a rare coincidence when $F . \Pi_{1}=F . \Pi_{3}(1-p)-$ p.c.

In spite of economy of results, the model has interesting and intuitive implications. As $p$ or $c$ rises the expected payoff of diverting falls. As a result, the payoff from sales through FPS may become higher, so case [4] becomes likely, corruption may fall. We recall that by [1] probability of detection tends to rise as proportion of people in PDS entitlement rises. Hence our model reflects the observation that greater universalisation implies less diversion of PDS grains.

Profit margins in FPS and open market are also found to be important. A high $\pi_{1}$, ceteris paribus, would go towards satisfaction of [4], implying no diversion. This is in line with the observation that financial viability of the PDS outlets is critical for a well-functioning PDS. We further observe that rising $\pi_{3}$ may allure the dealer towards diversion. Times of high food inflation are thus times of vulnerability for PDS.

\section{Conclusion}

The debate over public distribution system has taken many dimensions in recent decades. Although interesting arguments have been advanced from different sides, field studies suggest that delivering food through PDS is not as unviable a proposition as it is often made out to be. Many states have experimented with innovative measures which have proved to be successful. These include institutional changes, such as replacing the model of private shop owners with cooperative societies running the FPS. Or, by making use of technology such as mobile phones, which enhances the access of information of the beneficiary. In general, it appears that greater coverage of PDS has a salutary effect on the degree of corruption. The model presented here tries to capture these realities through a schematic model. Aside from extending the coverage of PDS, which is the first policy implication, the model cautions us about the fragility of the PDS at times when food price in open market is high. For the last few years food price inflation in India has been above 10 per cent per annum mark. Apart from exerting pressure on the living conditions of people whose income does not move with prices, high inflation may render PDS vulnerable. The second important policy implication therefore is that there is an urgent requirement to fix the PDS at times of high inflation. The third implication is the emphasis on the commercial viability of FPS. Low profits of distributing PDS foodgrain may allure many private shop owners to look for easy bucks through diversion. Until an alternative system of distribution is put in place matters of commercial incentive for the private shop owners cannot be overlooked. Finally, but very importantly, the element of monitoring is underscored. Monitoring can be achieved through institutional overhauls, for example, empowering the local community to oversee the functioning of PDS (this is related to the first point of extending the coverage; without ensuring greater participation of people at the grass roots simply extending PDS coverage may breed corruption). Monitoring could also be attained by taking the help of technology. Both these considerations should mould public policy. 


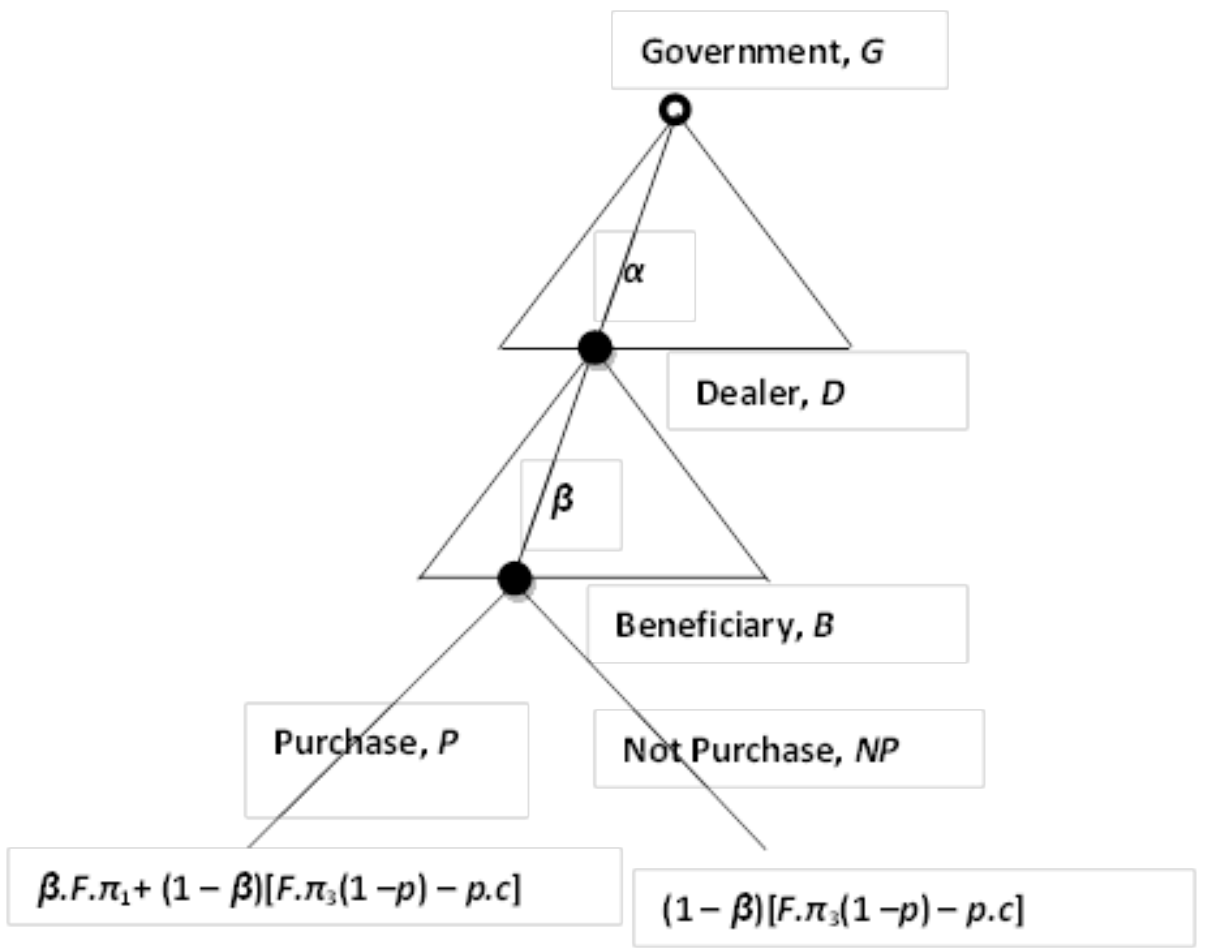

Figure 1: Game tree of the public distribution system, payoff of only $D$ is given

\section{References}

Basu, D. and D. Das (2013). In Cash or In Kind, Farms, Feasts and Famines, Himal Southasian, April, 56-68

Khera, R. (2011a). Revival of the Public

Distribution System: Evidence and

Explanations, Economic and Political Weekly, 46 (44 \& 46), 36-50

Khera, R. (2011b). Trends of Diversion of PDS Grain, Centre for Development Economics, Delhi School of Economics, Working Paper No. 198

Kotwal, A, M. Murugkar and B. Ramaswami (2011). PDS Forever? Economic and Political Weekly, 46 (12), 38-47

Sen, A. and Himanshu (2011). Why Not a Universal Food Security Legislation?, Economic and Political Weekly, 46 (12), 38-47

Soares, F. V. (2011). Brazil's Bolsa Família: A Review, Economic and Political Weekly, 46 (21), 55-60

Svederberg, P. (2012). Reforming or Replacing the Public Distribution System with Cash Trans- fers? Economic and Political Weekly, 47 (7), 5362

Yanes, P. (2011). Mexico's Targeted and Conditional Transfers: Between Oportunidades and Rights, Economic and Political Weekly, 46 (21), 49-54 